\title{
Author Correction: The Expression Analysis of Intestinal Cancer Stem Cell Marker Lgr5 in Colorectal Cancer Patients and the Correlation with Histopathological Markers
}

\author{
Shirin Salehzadeh ${ }^{1} \cdot$ Mandana Hasanzad $^{2,3} \cdot$ Azade Amini Kadijani $^{4} \cdot$ Abolfazl Akbari $^{5}$
}

Published online: 2 September 2019

(C) Springer Science+Business Media, LLC, part of Springer Nature 2019

\section{Author Correction: Journal of Gastrointestinal Cancer} https://doi.org/10.1007/s12029-01900295-w

The original version of this article unfortunately contained a mistake. In the author group section, the correct name of the first author is "Shirin Salehzadeh."

The authors apologize for this oversight and for any confusion it may have caused.

Publisher's Note Springer Nature remains neutral with regard to jurisdictional claims in published maps and institutional affiliations.

The online version of the original article can be found at https://doi.org/ 10.1007/s12029-019-00295-w

Abolfazl Akbari

akbari.ab@iums.ac.ir

1 Department of Genetics, Tehran Medical Sciences Branch, Islamic Azad University, Tehran, Iran

2 Department of Genetics, Faculty of Advanced Science and Technology, Tehran Medical Sciences, Islamic Azad University, Tehran, Iran

3 Medical Genomics Research Center, Tehran Medical Sciences, Islamic Azad University, Tehran, Iran

4 Basic and Molecular Epidemiology of Gastrointestinal Disorders Research Center, Research Institute for Gastroenterology and Liver Diseases, Shahid Beheshti University of Medical Sciences, Tehran, Iran

5 Colorectal Research Center, Iran University of Medical Sciences, Tehran, Iran 